\title{
Кто и как оценивает выборы: особенности экспертного опроса качества региональных выборов 13 сентября 2015 года в России ${ }^{1}$
}

\author{
М.А. ЗАВАДСКАЯ*, В.Д. БЕДЕРСОН**
}

\begin{abstract}
*Маргарита Андреевна Завадская - старший научный сотрудник, Лаборатория сравнительных социальных исследований, Национальный исследовательский университет «Высшая школа экономики»; научный сотрудник, Европейский университет в Санкт-Петербурге. Адрес: 191187, Санкт-Петербург, ул. Седова, д. 55, к. 1. E-mail: mzavadskaya@hse.ru

**Всеволод Дмитриевич Бедерсон - кандидат политических наук, младший научный сотрудник, Институт философии и права УрО РАН, сотрудник Центра сравнительных исторических и политических исследований ПГНИУ, старший преподаватель кафедры политических наук ПГНИУ. Адрес: 620990, Екатеринбург, ул. Софьи Ковалевской, д. 16. E-mail: vsbederson@gmail.com
\end{abstract}

Цитирование: Завадская М.А., Бедерсон В.Д. (2018) Кто и как оценивает выборы: особенности экспертного опроса качества региональных выборов 13 сентября 2015 года в России // Мир России. Т. 27. № 3. С. 82-106. DOI: 10.17323/1811-038X-2018-27-3-82-106

Метод оценки с помощьью экспертных опросов весьма распространен в современных сравнительных исследованиях, однако возникает вопрос, насколько надежными и валидными являются результаты подобных опросов, полученных в условиях (1) политизации предмета исследования (проблема чувствительности), (2) политического режима, характеризуемого экспертами как «электоральный авторитаризм», и (3) продолжающегося прочесса профессионализации экспертного сообщества. Основываясь на материалах экспертного опроса проекта Electoral Integrity Project, авторы исходят из предположения о том, что эти три фактора будут систематически влиять на характер экспертных оценок, оста-

\footnotetext{
1 Статья подготовлена в ходе проведения исследования/работы в рамках Программы фундаментальных исследований Национального исследовательского университета «Высшая школа экономики» (НИУ ВШЭ) и с использованием средств субсидии в рамках государственной поддержки ведущих университетов Российской Федерации «5-100».

Авторы благодарят коллектив международного проекта Electoral Integrity Project (Макса Громпинга и Феррана Мартинес-и-Кома), российскую команду проекта из Центра сравнительных исторических и политических исследований ПГНИУ (А.В. Гилева, А.В. Семенова, И.К. Шевцову), а также С.В. Патрушева, В.С. Ковина и всех экспертов, принявших участие в опросе.
} 
ваясь источниками смещчения (bias), которые необходимо учитывать при использовании результатов экспертных опросов в дальнейших исследованиях. Цель исследования - выявить, есть ли систематические смещтения в экспертных оценках, и если они есть, то каковы их источники. Результаты анализа показывают, что в экспертных оценках в качестве источников смещения имеют значение степень персональной «лояльности» или «оппозиционности» эксперта (голосования за партию власти или оппозицию), а также степень доверия телевидению.

Ключевые слова: смещение оценок, экспертный опрос, выборы, электоральный авторитаризм, Россия, региональная политика, методы исследований

\section{Введение, постановка задач, формулировка гипотезы}

Известный исследователь Эндрю Гелман, рецензируя в своем блоге некоторые материалы международного исследовательского проекта Electoral Integrity Project [The Electoral Integrity Project 2015], отмечает очевидные методологические риски применения метода экспертных опросов для оценки честности и справедливости проведения выборов в той или иной стране [Gelman 2017]. Э. Гелман остроумно иронизирует по поводу оценки экспертами выборов в Северной Корее как «умеренно честных» (moderate), а в штатах Северная Каролина, Огайо, Джорджия и некоторых других - хуже северокорейских. Также Э. Гелман рассуждает о примерах неконкурентных авторитаризмов (Северная Корея, Оман, Кувейт и др.), где экспертные опросы вообще не имеют смысла как диагностики качества выборов и где само электоральное событие вряд ли может быть названо выборами.

Аргументы Э. Гелмана, с одной стороны, верны и точны: нет большого содержательного смысла опрашивать экспертов, которые понимают, что они не могут оценивать политическую реальность не иначе, как позитивную. Это происходит потому, что зачастую проблема оценки связана с вопросом их собственной жизни и/или свободы. С другой стороны, такие методологические претензии хоть и справедливы, но только для закрытых авторитаризмов вроде Кувейта или Северной Кореи. Однако политическая карта мира предоставляет множество других не менее интересных случаев для изучения - например, конкурентные авторитаризмы, где эксперты могут оценивать выборы более или менее независимо и свободно.

Политолог Пол Гуд, имеющий большой опыт проведения качественных исследований в сложных полях, отмечает, что экспертные опросы могут быть источниками данных для политологов о тех или иных характеристиках недемократических режимов только при условии, что исследователь принимает то, что оценки таких экспертов являются, в том числе, проявлением эффектов политического режима [Goode 2010]. Проще говоря, политологам не стоит отказываться от экспертных опросов в недемократиях, помня о возможных смещениях в оценках экспертов, для которых оценка может быть не только технической процедурой, но и политическим актом, демонстрирующим их отношение к режиму. Учитывая эту дискуссию, авторы настоящей статьи постарались разобраться в том, что именно определяет экспертные оценки качества выборов на материале региональных выборов в России в сентябре 2015 г. 
Экспертные опросы - это распространенный инструмент для измерения концептов в сравнительных политических исследованиях - от уровня и профиля демократии [Freedom of the Press in Russia 2016; Многообразие демократии 2017] до позиционирования партий в идеологическом пространстве [Mair 2001; Manifesto Project 2016; Caslels, Mair 1984; Huber, Inglehart 1995] и уровня партийного клиентелизма и коррупции [Kitschelt 1995; The Data “Quality of Government” 2016]. Достоинством экспертных опросов является то, что эксперты полагаются на широкий спектр знаний и источников информации, в том числе недоступных наблюдателю извне [Mair 2001; Steenbergen, Marks 2007]. Методологическими преимуществами называют возможности прямой квантификации концептов и сверки надежности шкал (inter-expert reliability), гибкость опросника и дешевизну [Marks, Hooghe, Loveless, Rohrschneider, Steenbergen, Vachudova, Whitefield 2007].

С другой стороны, мы не всегда понимаем, как именно эксперт размышляет. Мы можем лишь догадываться о том, на какого рода информацию в своих оценках он опирается [Budge 2001; Steenbergen, Marks 2007]. Это неизбежная проблема субъективных экспертных оценок, которую можно скорректировать рабочими и прозрачными критериями отбора экспертов и увеличением количества наблюдений. Другая проблема связана с качеством, распространением и доступом к необходимой для оценки информации: так, в посткоммунистических демократиях Центральной и Восточной Европы исследователи выражали обеспокоенность нестабильностью оценок в условиях недостаточной или искаженной информации (information-poor environment).

Экспертный опрос как метод опирается на подбор экспертов таким образом, чтобы они соответствовали ряду критериев (см. ниже), подтверждающих наличие необходимой экспертизы. Однако в действительности невозможно ex ante определить политические предпочтения эксперта, степень их влияния на оценки эксперта. Экспертный опрос как исследовательский метод не подразумевает нормативности в отношении компетентности эксперта, точнее, компетентность эксперта имеет значение, но она не заключается в его «интеллектуальной аскетичности», а, наоборот, эффективность метода связана с субъективной оценкой эксперта, дающей ему основания выражать точку зрения, которая может быть названа «экспертной».

В российских условиях проблема проведения и интерпретации результатов опросов усугублена (1) особенностями политического режима, характеризуемого экспертами как «электоральный авторитарный» [Голосов 2008], (2) вытекающей отсюда проблемой неизбежной политизации большинства вопросов и (3) продолжающимся процессом становления профессионального экспертного сообщества [Титков 2013]. Мы исходим из предположения о том, что эти три фактора являются источниками систематического смещения (systematic error, bias), которые необходимо учитывать при использовании результатов экспертных опросов в дальнейших исследованиях.

В настоящей статье мы представляем результаты экспертного опроса о качестве электоральных процессов в рамках региональных исследований международного исследовательского проекта Electoral Integrity Project по итогам волны региональных выборов 2015 г. [The Electoral Integrity Project 2015]. Как уже отмечалось, выборы являются одной из наиболее политизированных тем, поэтому именно опыт данного опроса позволяет ответить на исследовательский вопрос о том, каковы детерминанты оценки экспертами качества электоральных процессов. 
Также работа преследует и более общие цели: описание состояния современного российского экспертного сообщества в области электоральной экспертизы и поиск ответа на вопрос «Каковы пределы возможностей экспертных опросов в условиях электорального авторитаризма?».

Разброс оценок экспертов, как будет показано ниже, определяется не только разнообразием идеологических предпочтений самих экспертов и их доверием существующим политическим институтам, но и индивидуальной стратегией голосования эксперта за партию власти или оппозицию.

Статья состоит из краткого описания основных источников смещений оценок в экспертных опросах в сравнительных политических исследованиях, введения в контекст российских выборов сентября 2015 г. методики экспертного опроса Electoral Integrity Project, анализа описательной статистики, представления результатов регрессионного анализа и источников систематических смещений, а также наших ключевых выводов и научной дискуссии.

\section{Особенности экспертных опросов в российском контексте}

Ни один из методов сбора данных не дает идеального отражения реальности; каждому инструменту присущи свои специфические недостатки. Задача исследователя - не столько искать самый лучший инструмент, сколько осознавать ограничения тех, что имеются в наличии. Экспертные опросы привлекательны своей дешевизной и гибкостью, однако им также присущи серьезные недостатки - субъективность, информационные асимметрии и ограничения, связанные с дистанцией между событием и временем оценки, вмешивающиеся предпочтения и поведение [Budge 2001; Steenbergen, Marks 2007]. Как правило, в исследованиях используются усредненные индивидуальные суждения.

Помимо общих недостатков, исследователи обнаружили, что дисперсия оценок систематически увеличивается, когда речь идет об оценках, например, не об умеренных и крупных партиях, а о малых, новых и экстремистских партиях [Marks, Hooghe, Loveless, Rohrschneider, Steenbergen, Vachudova, Whitefield 2007, p. 24]. Наконец, некоторые исследователи предположили, что оценка идеологических позиций партий будет особенно затруднена в новых демократиях Центральной и Восточной Европы, так как партийные системы еще не оформились, партии менее укоренены, и экспертам сложнее работать в условиях ограниченного доступа к надежной информации по сравнению с Западной Европой [Whitefield, Vachudova, Steenbergen, Rohrschneider, Marks, Loveless, Hooghe 2007]. Проанализировав расхождения десятка баз данных о выборах, Каролин ван Хэм обнаружила, что разброс оценок увеличивается по мере ухудшения качества выборов [van Ham 2015].

Тем не менее сопоставление оценок различных экспертных опросов указывает, что, несмотря на эти недостатки, экспертные опросы дают менее смещенные оценки даже в сравнении с кодированием первичных и вторичных данных [Marks, Hooghe, Loveless, Rohrschneider, Steenbergen, Vachudova, Whitefield 2007, p. 26]. Таким образом, задача заключается в отделении случайной ошибки (random error) от систематической (systematic error or bias), 
которая смещает оценки относительно истинного параметра. Систематическая ошибка - это «скос, который измеряет разницу между средним экспертным суждением и истинным значением» [Marks, Hooghe, Loveless, Rohrschneider, Steenbergen, Vachudova, Whitefield 2007, p. 51].

Возвращаясь к контексту российских выборов, наиболее очевидной, вопервых, является проблема нестабильности оценок в условиях недостаточной или искаженной информации (information-poor environment). Причинами нестабильности оценок может быть неравномерный доступ к надежной информации и качество информационной среды в целом. Российский политический режим c 2007 г. квалифицируется политологами как «электоральный авторитаризм» [Голосов 2008; Freedom of the Press 2016; Многообразие демократии 2017], для которого характерно систематическое нарушение принципов честных и свободных выборов (free and fair elections), отказ в праве доступа политической оппозиции, не аффилированной с инкумбентом, на электоральную арену или же систематическое учинение институциональных и процедурных препятствий потенциальным политическим конкурентам. Именно современные электоральные авторитаризмы подвержены информационным асимметриям разного происхождения - от практик цензуры и неравного доступа к каналам коммуникации до недостатка профессионализма². Наконец, проблему представляет возможность общения с самими экспертами в наиболее закрытых регионах.

Во-вторых, проведение экспертных опросов в контексте электорального авторитаризма само по себе представляется методологическим вызовом, поскольку практика сбора данных по чувствительным вопросам может вызывать сомнения из-за такого явления, как «фальсификация предпочтений» [Kuran 1997], характерного для недемократических обществ. Опрашиваемые могут умышленно или неумышленно не высказывать свои истинные предпочтения или мнения, на всякий случай избегая потенциально рискованных и чувствительных тем. Тема выборов является одной из наиболее политизированных, именно поэтому стоит ожидать, что многие эксперты откажутся от участия в опросе или будут давать более положительные оценки. Количество отказов в том или ином регионе может также зависеть и от степени авторитарности региона и ожидаемых санкций.

В-третьих, в таких режимах следует ожидать большую поляризацию идеологических позиций в первую очередь по отношению к участникам выборов и политическим институтам. Поскольку ставки на таких выборах гораздо выше [Przeworski 2000], то и различия между «экспертами-лоялистами» и «экспертами-оппозиционерами» будут более выраженными. С другой стороны, феномен различий оценок между экспертами, поддержавшими победителей, и теми, кто поддержал проигравших (winner-loser gap), существует практически в любом политическом контексте. Не стоит полагать, что это явление присуще исключительно авторитарной политике, однако авторитаризм усиливает этот разрыв. Наконец, важно учитывать характеристики экспертного сообщества, опыт и квалификацию респондентов [Титков 2013].

Для выявления такого рода систематических скосов используется либо кроссвалидация разных опросов по сходной теме с последующим анализом расхожде-

\footnotetext{
2 Данная проблема известна как adverse selection, когда выбор на рынке труда регулярно делается в пользу лояльных, а не компетентных [Acemoglu, Sonin, Egorov 2010].
} 
ния между ними [Marks, Hooghe, Loveless, Rohrschneider, Steenbergen, Vachudova, Whitefield 2007; van Ham 2015], либо проводится регрессионный анализ оценок на уровне экспертов. В нашем распоряжении есть лишь один экспертный опрос, поэтому кросс-валидация возможна лишь с привлечением оценок наблюдателей, однако и в этом случае имеется ряд серьезных проблем. Во-первых, независимые наблюдатели присутствовали далеко не во всех регионах: более того, отсутствие наблюдателей в тех или иных регионах нельзя считать случайным. Во-вторых, частота нарушений, зафиксированных наблюдателями и избирателями [Карта нарушений 2015], также может отражать скорее осведомленность избирателей о возможных нарушениях и даже относительную либеральность региона, нежели реальное качество выборов.

Основываясь на указанных выше источниках, влияющих на оценку экспертов, мы использовали суммарный индекс качества электоральных процессов PEI индекс (Perception of Electoral Integrity) - в качестве зависимой переменной, а индивидуальные характеристики экспертов - как независимые переменные. Для обнаружения смещения оценок из-за информационных асимметрий был задействован уровень доверия эксперта СМИ (телевидению), его доступ к инсайдерской информации в качестве политконсультанта, журналиста, члена избиркома, наблюдателя. Для тестирования связи между политической позицией эксперта и его оценкой мы использовали данные о том, за кого проголосовал эксперт либо испортил ли он бюллетень. Кроме того, мы полагаем, что работа эксперта в органах власти или иная форма ангажированности также могли влиять на его оценки.

\section{Экспертный опрос о качестве электоральных процессов: контекст, концепция и метод}

Помимо международных наблюдателей в России достаточное распространение, особенно во второй половине $2000-$ х гг., получили независимые центры наблюдения за качеством электоральных процессов, среди которых в первую очередь необходимо назвать Ассоциацию в защиту избирательных прав «Голос». Эксперты «Голоса» занимались подготовкой наблюдателей, совершенствованием нормативно-правовой базы избирательного процесса в России, мониторингом качества выборов ${ }^{3}$. Кроме «Голоса», в рамках электорального цикла 2011-2012 гг. активно работали и другие гражданские группы, следившие за качеством выборов, например, «Гражданин наблюдатель» ${ }^{4}$, РосВыборы ${ }^{5}$, в регионах России образовывались собственные группы наблюдения [Пермский наблюдатель; Дальневосточный наблюдатель; Гражданин наблюдатель в Новгородской области]. По экспертным оценкам, результаты мониторингов выборов такими независимыми группами наблюдателей, зафиксировавшими множество процессуальных нарушений и фальсификаций, послужили триггером протестных митингов зимой 2011-2012 гг. в России [Rose, Sedziaka 2014; Завадская, Савельева 2014; Green 2014].

\footnotetext{
www.kartanarusheniy.org/

4 www.nabludatel.org/

5 www.rosvybory.org/
} 
13 сентября 2015 г. основной организацией, осуществлявшей долгосрочное наблюдение за выборами в 10 из 21 региона, был «Голос». Долгосрочное наблюдение реализовывалось на выборах 8 из 11 региональных легислатур и 14 из 25 губернаторских выборов (включая Самару и Махачкалу). Согласно заключению «Голоса», данные выборы отклонились от «принципов и стандартов демократических выборов, в первую очередь манипулированием избирательным законодательством по политическим причинам незадолго до выборов и созданием очевидных условий доступа к административным ресурсам в целях способствования успеху определенных кандидатов и партий. Особые опасения вызывают случаи давления и осуществления насилия в отношении наблюдателей: массовый недопуск общественных наблюдателей под различными предлогами на избирательные участки» [Analytical Report 2015].

Следует подчеркнуть, что известное клише «честные и свободные выборы» отсылает к тому, насколько выборы соответствуют закону и международным правовым нормам и свободны от манипуляций, направленных на искажение воли избирателей. В академической литературе существует несколько концептов, которые так или иначе характеризуют «качество» выборов [Birch 2011; Elklit, Svensson 1997], акцентируя либо нарушение конкретного избирательного законодательства [Lehoucq 2003], либо же любого рода «авторитарные» манипуляции [Schedler 2002; Schedler 2006]. Одной из новаций в современной политической науке является подход, предложенный П. Норрис [Norris 2014], где качество электоральных процессов, или electoral integrity, - это «международные конвенции и глобальные нормы, универсально применимые ко всем странам мира на всех стадиях избирательного цикла, включая довыборный период, предвыборную кампанию, день голосования и период после выборов. Напротив, понятие «электоральное злоупотребление», или electoral malpractice, используется для указания на нарушения этих глобальных норм» [Norris 2013, р. 564]. Иными словами, данное определение обращает внимание не только на день голосования, но на весь избирательный цикл, включая избирательное законодательство, регистрацию партий и избирателей, ведение кампании и последовавшие после голосования события. Следовательно, нарушения и злоупотребления могут возникнуть не только в день голосования, но и на любой другой стадии избирательного цикла (как это показано на рисунке 1), включающего в себя законы, дискриминирующие определенные партии или группы избирателей, нарезку округов (джерримандеринг), финансовые нарушения, ангажированность членов избирательных комиссий, принуждение к голосованию, покупку голосов, фальсификацию и селективное применение санкций. Стоит отметить, что не все нарушения являются централизованными и заранее спланированными, всегда есть вероятность, что они совершаются по ошибке или в результате отсутствия соответствующих компетенций (malpractice vs mispractice).

В научной литературе подчеркивается решающая роль качества национальных выборов на явку избирателей [Birch 2010; Nikolayenko 2015], легитимность и стабильность режимов [Norris 2014], а также вероятность массовых протестов [Tucker 2007; Beaulieu 2014]. Вместе с тем, наблюдается дефицит исследований о том, как качество выборов варьируется на региональном уровне, от чего это зависит, и какие это имеет последствия для режима. Для того чтобы ответить на эти вопросы в контексте электорального авторитаризма, необходимо убедиться в том, что является детерминантом оценок экспертов и каково состояние экспертного сообщества в стране. 


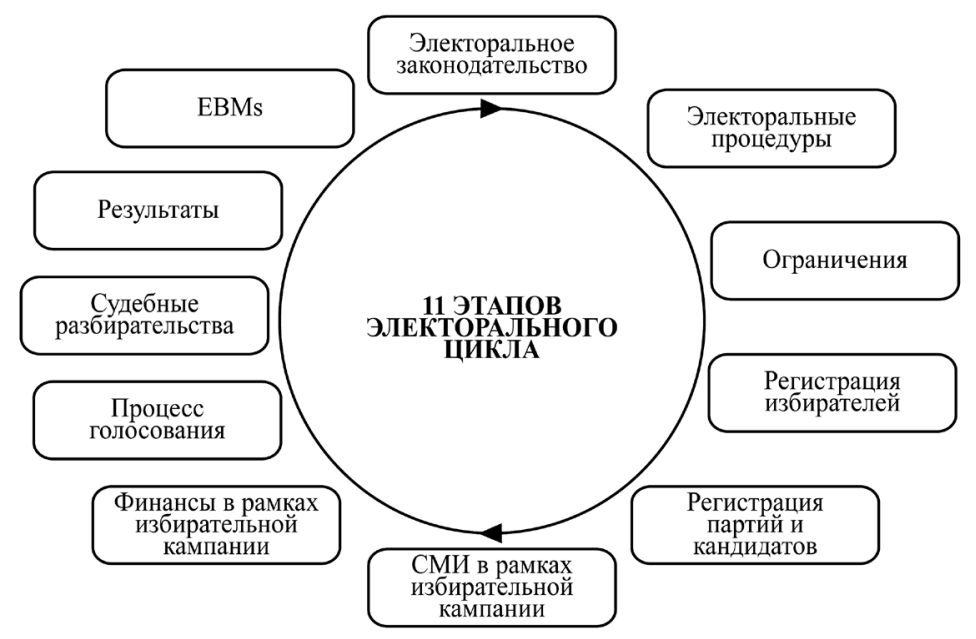

Рисунок 1. Избирательный цикл и качество электоральных процессов ${ }^{6}$

Как свидетельствует обширный пласт зарубежной литературы, даже в электоральных демократиях встречаются анклавы авторитарного доминирования тех или иных политических групп в пределах одного региона страны, что получило название «субнациональный авторитаризм» [Gibson 2013; Гельман 2012]. Следуя этой логике, политический режим не является идентичным во всех регионах страны. Россия остается одной из тех уникальных стран, в составе которых функционирует огромное число субнациональных единиц. Поэтому было бы наивно полагать, что во всех регионах установлен идентичный режим даже в рамках электорального авторитаризма: для одних регионов характерна большая доля политической конкуренции, для других - меньшая. Следовательно, и качество электоральных процессов (electoral integrity) [Norris 2014; Турченко 2015] или же, наоборот, комбинация тех или иных форм электоральных злоупотреблений (electoral malpractice) [Birch 2011] на региональном уровне должны отличаться друг от друга. Разумеется, наличие политической конкуренции еще не дает оснований считать тот или иной регион демократическим, однако этот факт задает необходимую вариацию на субнациональном уровне, которую можно исследовать посредством сравнительного анализа и количественных техник.

Для операционализации и измерения качества электоральных процессов посредством экспертных оценок было разработано 49 индикаторов, сгруппированных в 11 категорий, отражающих полноценный избирательный цикл. Результирующий показатель представляет собой аддитивный индекс, варьирующий от 0 до 100, где 100 - это наилучшая оценка качества выборов. Экспертный опрос был проведен спустя неделю после дня голосования 13 сентября 2015 г.: в каждом регионе, где прошли выборы, были отобраны от 9 до 40 экспертов, которые получили на свои электронные адреса приглашение принять участие в опросе

6 [Norris 2014], EMBs - electoral management bodies, система избирательных комиссий. 
путем заполнения опросной формы 7 . База данных экспертов подбиралась в течение лета 2015 г., ключевой критерий отбора эксперта - его осведомленность о предвыборной ситуации в регионе, также части экспертов было предложено оценить качество выборов в нескольких знакомых им регионах. Всего база данных экспертов включала в себя 536 чел., из которых 172 приняли участие в опросе. Уровень респонсивности опроса (response rate) составлял $32 \%$. Также были установлены качественные рамки отбора экспертов: им мог стать политолог (или представитель смежной дисциплины - права, социологии, экономики, антропологии, математики или статистики), у которого имелись релевантные публикации или же он продемонстрировал экспертное знание об электоральной политике в том или ином регионе иным публичным образом. Мы опирались на такие критерии, как членство в релевантных исследовательских группах, профессиональных ассоциациях и сетях, публикации в профильных журналах (сборниках, книгах, работа в университете или колледже преподавателем профильного предмета.

Стоит отметить, что в группе недостижимости можно обозначить экспертов, связанных с органами власти ввиду предполагаемого малого количества ответов именно членов этой группы, что можно объяснить принципом «им есть, что терять», и что само по себе может быть интерпретировано как эффект экспертных опросов в недемократических политических режимах. Также к группе недостижимости мы отнесли политтехнологов в силу определенной профессиональной закрытости сообщества и коммуникативной сложности взаимодействия политологов из академической среды и политтехнологов.

Проблема небольшого количестве экспертов в некоторых регионах была решена методом множественной реконструкции данных (multiple imputation), широко применяемой в эконометрике (т.е. пропущенные данные были восстановлены с помощью системы регрессионных уравнений ${ }^{8}$.

\section{Наблюдаемые закономерности и анализ описательной статистики}

В результате онлайн-опроса был получен рейтинг регионов, построенный в зависимости от оценки экспертами качества электоральных процессов. Строго говоря, данный рейтинг не отражает реальный уровень нарушений, он скорее указывает, как экспертное сообщество воспринимает качество выборов в данном регионе. «Чемпионами» по качеству выборов, получившими наивысшие оценки экспертов, оказались Белгородская, Тамбовская и Иркутская области, а «аутсайдерами» - Кемеровская, Магаданская и Костромская (рисунок 2). При этом выборы в Костроме и Иркутске были отмечены чередой скандалов, связанных с регистрацией партийных списков ${ }^{9}$. Выборы в Белгородской области не привлекли внимания федеральных СМИ, и то, насколько гладко прошли выборы в этом регионе с точки зрения соответствия нормам избирательного законодательства, оценить сложно.

\footnotetext{
7 Если эту статью читает политолог или социолог из любого региона, где были выборы в 2015 г., то существует высокая вероятность, что он был приглашен к участию в опросе.

8 Такой метод допустим в ситуациях, когда данные отсутствуют случайным образом.

9 В Иркутске победу в губернаторской гонке одержал кандидат, поддержанный КПРФ
} 


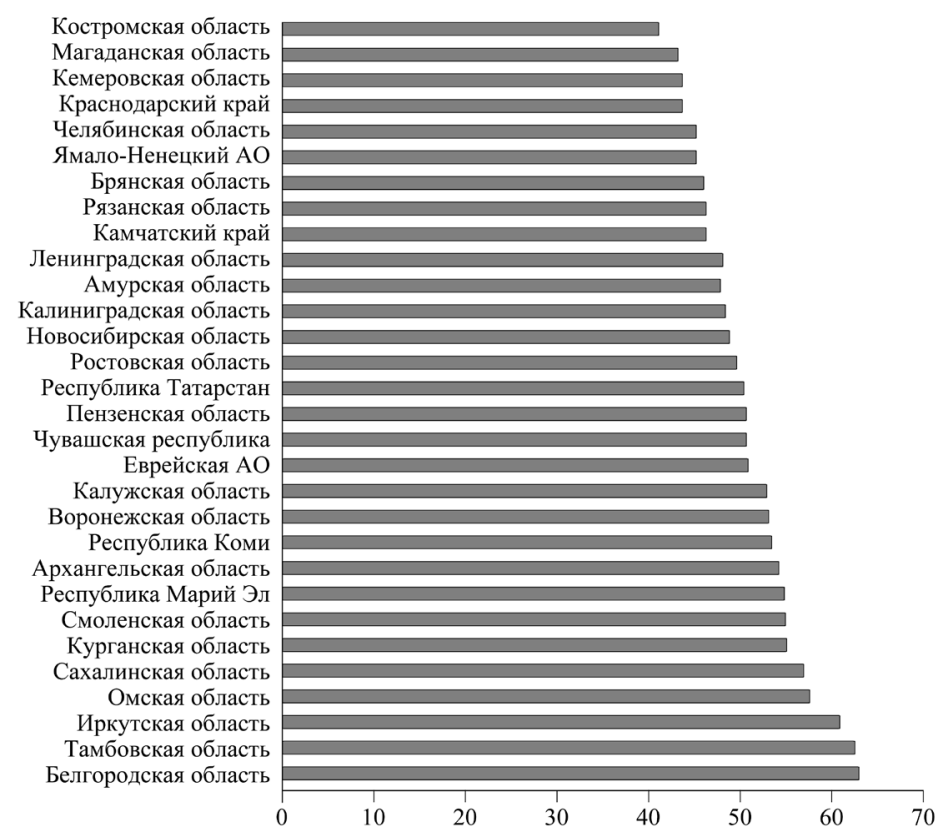

Рисунок 2. Индекс восприятия качества электоральных процессов в регионах, сентябрь 2015

Эксперты, участвовавшие в опросе, были рекрутированы преимущественно из академической сферы (региональных университетов и институтов системы РАН) (75\%); также в качестве экспертов были задействованы журналисты $(11 \%)$ и представители бизнеса (8\%), прошедшие фильтры на наличие необходимых экспертных знаний (рисунок 3).

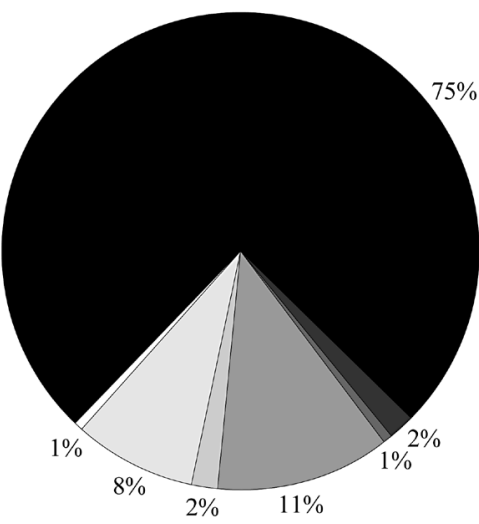

университетские работники

госслужащие

$\square$ избирательные комиссии

$\square$ журналисты

$\square$ юристы

$\square$ бизнесмены

политики

Рисунок 3. Распределение экспертов по сферам занятости, \% 
Экспертный опросник включал в себя вопросы, направленные на выявление политического бэкграунда экспертов (рисунок 4). Любопытно, что большинство из них обозначили отсутствие у себя опыта как в сфере государственного наблюдения или организации выборов (например, работы в структурах избирательных комиссий), так и в области негосударственного наблюдения за выборами. При этом тех, кто имел опыт негосударственного наблюдения, оказалось значительно больше, чем тех, кто работал в избирательных комиссиях. На наш взгляд, это может свидетельствовать о выборе большинством экспертов позиции комментатора, а не участника, что косвенно может указывать на склонность отобранных экспертов к профессиональной и неангажированной оценке выборов.

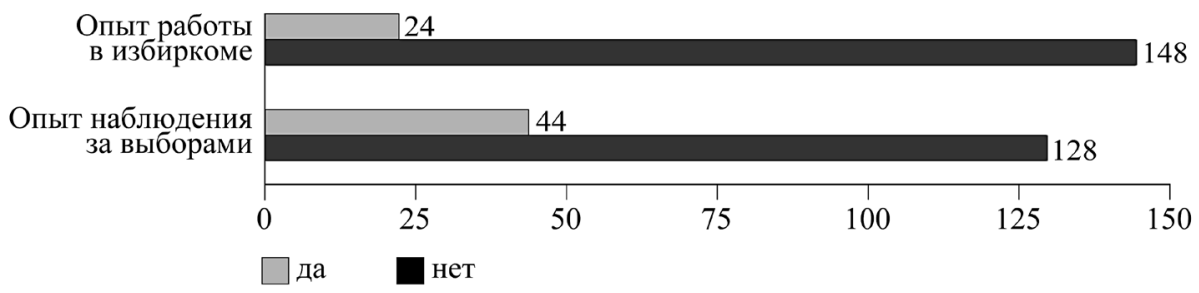

Рисунок 4. Опыт работы в организации выборов и негосударственного наблюдения за выборами, количество экспертов

Один из вопросов предполагал оценку идеологических предпочтений экспертов в лево-правом континууме (имеется ввиду экономический аспект). Экспертам было предложено оценить свои взгляды по шкале от 1 до 10, где 1 - крайне левые, а 10 - крайне правые. Представленный на рисунке 5 график показывает, что большинство экспертов придерживались центристских взглядов, при этом в процентном соотношении сторонников правых насчитывалось больше, чем адептов левых взглядов. Однозначно трактовать график не представляется возможным в силу того, что среди экспертов представления о правых и левых взглядах могли существенно варьироваться. Однако совместное распределение самоидентификации экспертов на лево-правом континууме и оценок выборов показывает, что значимая связь между идеологическими пристрастиями экспертов и их оценкой выборов отсутствует (рисунок 6$)$.

Необходимо отметить, что наиболее важной является связь между тем, за кого голосовали эксперты, и их оценкой качества выборов. Считается, что в условиях «электорального авторитаризма» сама практика оценивания ведет к поляризации или расколу экспертного сообщества на «прорежимных» и «оппозиционных»: первые склонны завышать оценку качества прошедших выборов, вторые-занижать, по умолчанию принимая, что властные структуры вмешиваются в электоральную кампанию на всех ее этапах. В академической литературе данный феномен получил название winner-loser gap (разница в оценках между «победителями» и «проигравшими»).

В ходе анализа выяснилось, что оценки «победителей» на 20 процентных пунктов выше, чем у «проигравших» (рисунок 7), при этом оценки тех, кто отказался сообщить о своих электоральных предпочтениях, на 10 процентных пунктов 
ниже, чем у «победителей», но тем не менее выше, чем у «проигравших», а оценки испортивших бюллетень чуть выше, чем у «проигравших». Подобное распределение свидетельствует о высокой степени политизации экспертного сообщества, но не по линии более абстрактного лево-правого континуума, а по линии отношения к режиму. Наконец, значительная доля тех, кто не стал раскрывать свои электоральные предпочтения, также свидетельствует о чувствительности вопроса и возможном эффекте фальсификации на уровне экспертного сообщества.

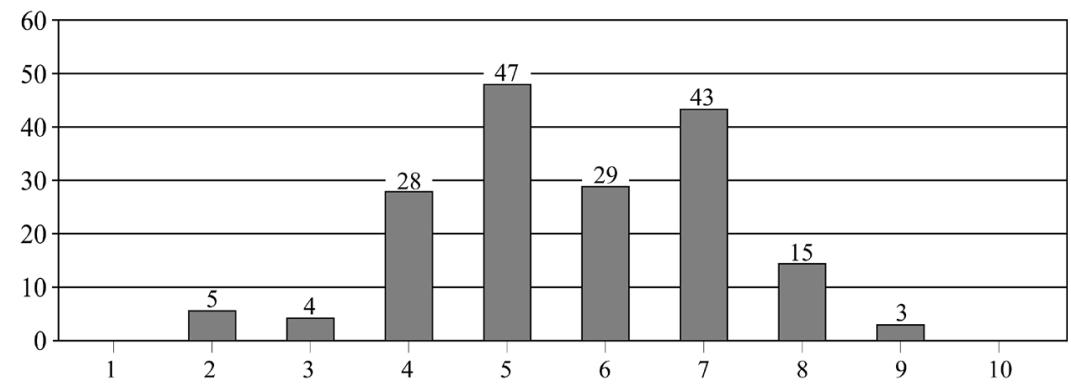

Рисунок 5. Распределение экспертов на лево-правом континууме

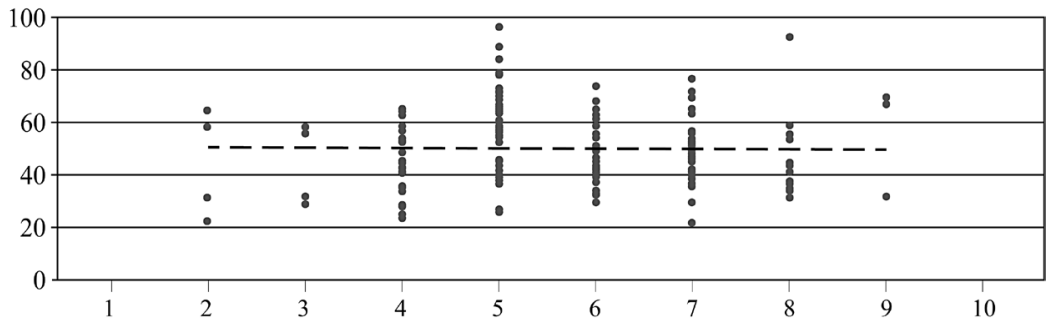

- РЕІ индекс качества выборов, импут. - - - регрессионная линия

Рисунок 6. Самоидентификация экспертом на лево-правом континууме и оценка качества выборов

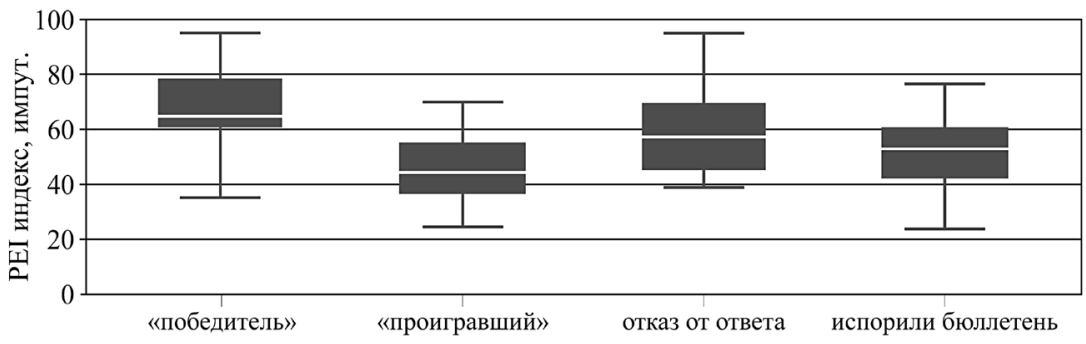

Рисунок 7. Разница в оценках между «проигравшими» и «победителями» (winner-loser gap) 
Ввиду того, что в большинстве регионов, где в сентябре 2015 г. прошли выборы, победу одержали кандидаты в губернаторы, поддержанные «Единой Россией», или эта партия победила на выборах в региональный парламент ${ }^{10}$, мы можем сделать вывод о наличии связи между лояльной режиму ориентацией эксперта и его высокой оценкой качества прошедших выборов, при этом справедливо и обратное: «проигравшие» эксперты выставили более скептичные оценки. Различие между теми, кто сообщил о своем выборе, и теми, кто не ответил на данный вопрос опросника, является статистически значимой. В то же время разброс оценок в категории несообщивших о своих предпочтениях настолько велик, что нельзя выявить сколько-нибудь значимые отличия от иных групп. Очевидно, эта группа включает в себя и «проигравших», и «победителей», которые по разным причинам воздержались от ответа на вопрос. Группа экспертов, испортивших бюллетень, также статистически значимым образом отличается от группы «победителей». Примечательно, что условных «абсентеистов» было достаточно много $(17,4 \%)$, а их оценки качества выборов оказались несколько выше, чем оценки тех, кто ходил и голосовал за оппозицию, однако эта разница не является статистически значимой.

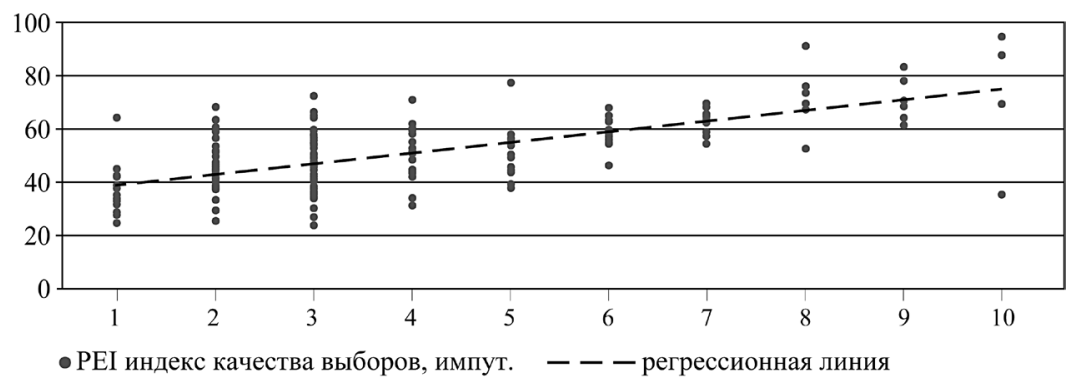

Рисунок 8. Доверие Правительству РФ и оценка качества электоральных процессов

Значение для оценки качества выборов имеет также и степень доверия эксперта политическим институтам, в частности, Правительству РФ: чем ниже доверие, тем ниже оценка и наоборот (рисунок 8). Выборы в Иркутской области, для которых был характерен средний уровень доверия правительству, но положительная оценка качества выборов, объясняется высоким уровнем конкуренции кандидатов, противостоянием кандидата от партии власти и кандидата от КПРФ, который победил во втором туре. Выборы в Брянской области (где наблюдался высокий уровень доверия правительству, но неудовлетворительная оценка качества выборов), напротив, объясняется низкой конкурентностью выборов, «зачисткой» политического поля под кандидата, поддержанного Кремлем и «Единой Россией». Здесь

\footnotetext{
10 За исключением ситуации в Смоленской области, где губернаторскую гонку выиграл кандидат, хоть и относящийся к ЛДПР, но выступающий на выборах в качестве инкумбента, и широко освещенного в СМИ случая проведения второго тура в Иркутской области и победы кандидата от КПРФ.
} 
КПРФ не выдвигала своего кандидата, представитель ЛДПР был номинирован на должность сенатора при условии победы инкумбента, а кандидат от «Справедливой России», не сумевшей выстроить в регионе реально действующую партийную структуру, набрал лишь 7,9\% голосов, при этом кандидат от партии «Патриоты России» - почти на 2\% больше $(9,6 \%)$.

Примечательно, что еще более сильная связь наблюдается между доверием экспертов телевизионному эфиру и значением PEI индекса. Рисунок 9 наглядно демонстрирует прямую связь между уровнем доверия телевидению и оценкой качества выборов: там, где эксперты, очевидно, смотрели телевизионные программы и доверяли полученной посредством ТВ-информации, оценка качества проведенных в регионе выборов была выше. Вероятно, телеэфир имеет значение при формировании собственной позиции не только для широких электоральных масс, но и для искушенного специальным знанием экспертного сообщества. С другой стороны, большинство экспертных оценок группировались на более низких значениях уровня доверия, а по мере роста доверия количество экспертов снижалось, что свидетельствует о наличии гетероскедастичности - неоднородности дисперсии случайной ошибки регрессионной модели, т.е. наличия пропущенной переменной. Содержательно это означает, что существует некая третья переменная, которая объясняет, почему число экспертов по мере роста доверия телевидению повышается: например, это может быть результатом «фальсификации предпочтений» либо той или иной формой ангажированности.

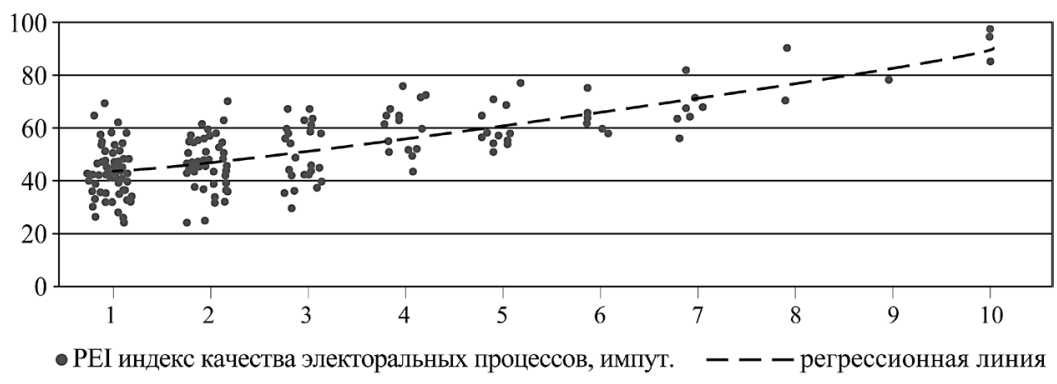

Рисунок 9. Доверие телевидению и оценка качества электоральных процессов Примечание: 1 - низкий уровень, 10 - высокий уровень.

В западной литературе институт выборов традиционно рассматривается как инструмент демократии [Powell 2000; Manin, Przeworski, Stokes 1999]. Однако возникновение аналогичного института в бывших коммунистических странах и его функционирование могут отличаться в новом контексте. Поэтому, опираясь на отечественные исследования, касающиеся адаптации института выборов к российским политическим реалиям [Панов 2008; Павлова, Патрушев, Филиппова 2012], мы ввели отдельный вопрос о том, что для респондента означает институт выборов в первую очередь: механизм консолидации общества, актуализацию идентичности, сплочения и единения или же процедуру селекции политических лидеров, поддержание работы государственного механизма. Эта переменная отражает 
нормативные представления экспертов об институте выборов в российских реалиях, а также может влиять на систему критериев, относительно которых эксперты оценивали выборы в своем регионе.

На рисунке 10 показано совместное распределение степени акцепции экспертами того, что выборы призваны демонстрировать единство граждан и нации, и PЕI индекса. Те эксперты, которые в наибольшей степени согласны с этой интерпретацией выборов, оценивали выборы более оптимистично, впрочем, эта связь достаточно слабая.

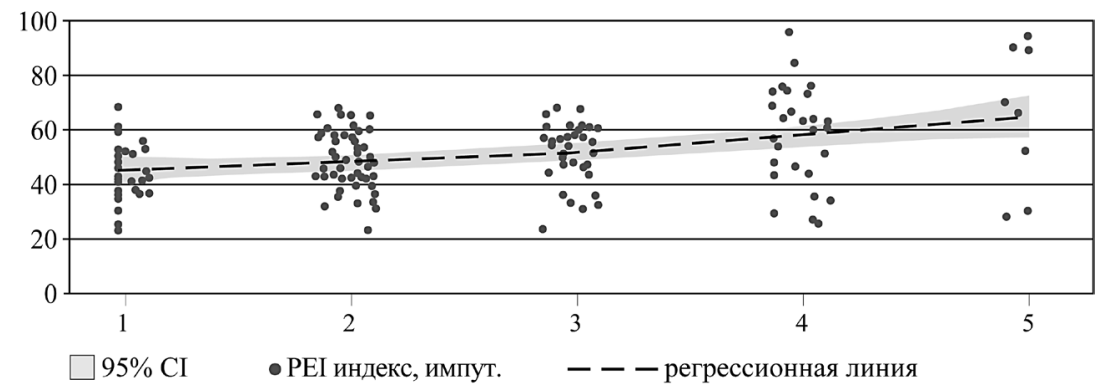

Рисунок 10. Распределение мнений экспертов в вопросе отношения к выборам как механизму консолидации общества

Таким образом, основными источниками смещения экспертных оценок являются стратегия голосования эксперта и доверие политическим институтам; эти переменные позволяют выявить паттерны определения качества выборов в нынешнем российском контексте.

\section{Результаты регрессионного анализа: источники смещения экспертных оценок}

Прежде чем окончательно удостовериться в том, что именно стратегии голосования и доверие политическим институтам являются ключевыми предикторами экспертных оценок, необходимо проверить альтернативные объяснения. В данной части статьи мы представляем результаты многомерного регрессионного анализа, где основной зависимой переменной становится значение PEI индекса, измеряющего качество электоральных процессов в регионе на уровне эксперта.

В таблице 1 представлены шесть моделей, которые оценивают силу и значимость факторов, способных влиять на оценки экспертов. Модель 1 включает только контрольные переменные - пол, возрастную группу, субъективную оценку эксперта уровня своей осведомленности о выборах в конкретном регионе, а также основную форму занятости эксперта (работа в университете или некоммерческом секторе). Модель 2 содержит переменную, означающую наличие у эксперта непосредственного доступа к инсайдерской информации о выборах в качестве наблю- 
дателя, члена избиркома, госслужащего, технолога или журналиста. Модель 3 оценивает влияние стратегии голосования эксперта и разрыв между «победителями» и «проигравшими». Модель 4 тестирует эффект уровня доверия телевидению и системе избирательных комиссий. Наконец, Модели 5 и 6 включают только наиболее сильные предикторы: тип стратегии голосования и уровень доверия политическим институтам в целом. Поскольку переменные, измеряющие уровень доверия эксперта парламенту, правительству, полиции, армии, судам, избиркомам, партиям и телевидению, коррелируют весьма значительно, то уровень доверия выражен с помощью общего индекса, объединяющего доверие режиму в целом ${ }^{11}$.

Как мы видим, пол эксперта, равно как и его возраст, не влияет на оценку выборов; лишь в Модели 4 выделяются некоторые возрастные группы, которые склонны оценивать выборы более оптимистично по сравнению с самой молодой группой экспертов (до 30 лет). Наиболее сильный эффект наблюдается у самой старшей группы экспертов (старше 70 лет): они оценивают выборы в среднем на 11 пунктов оптимистичнее, чем самые молодые. Эксперты, работающие в университетах, ничем не отличаются от тех, кто работает в иных сферах занятости. В то же время сотрудники НКО, в том числе связанные с независимым наблюдением за выборами («Голос»), систематически более критично оценивают выборы примерно на 6 пунктов. Модель 2 тестирует эффект «инсайдерства», однако не обнаруживает значимого эффекта.

Эксперты, проголосовавшие за проигравшие партии или кандидатов (преимущественно «Яблоко», КПРФ, реже ЛДПР), оценивали выборы на 22,3 пункта ниже, чем проголосовавшие за «победителей» (преимущественно «Единая Россия», в Иркутске - КПРФ). Испортившие бюллетень оценивали выборы на 11 пунктов ниже, чем поддержавшие «победителей». Однако разница между испортившими и отказавшимися от ответа на вопрос оказалась гораздо меньше. Во-первых, это указывает на то, что разброс оценок в этой группе довольно большой, там присутствовали эксперты, критически настроенные «против всех», и, возможно, те, кто уклонился от прямого ответа на вопрос. Примечательно, что существенная разница между группой уклонившихся от ответа и группой «лояльных» отсутствовала, что может свидетельствовать о закрытости лояльных экспертов, а также о «фальсификации предпочтений наоборот», когда выражение поддержки инкумбента в некоторых профессиональных кругах считывалось неоднозначно. Во-вторых, этот факт демонстрирует, что оценки могли быть существенно искажены как «оппозиционерами», так и «лояльными».

Как только мы вводим переменную, измеряющую уровень доверия эксперта политическим институтам (см. Модели 5 и 6 mаблищь 1), то разница между группой испортивших бюллетень и «лояльными» исчезает. Это свидетельствует о том, что, во-первых, доверие институтам и стратегия голосования - не одно и то же, хотя теоретически эти параметры должны быть связаны друг с другом, а вовторых, что среди испортивших бюллетень были как те, кто доверял, так и те, кто не доверял политическим институтам. Среди проголосовавших за проигравшие партии подавляющее большинство экспертов власти не доверяли, среди остальных картина менее однозначная.

11 Индекс представляет собой значения фактора (factor scores), полученного в результате факторного анализа нескольких переменных, измеряющих уровень доверия различным политическим институтам (principal component). 
Таблица 1. Детерминанты экспертных оценок: результаты регрессионного анализа, зависимая переменная - PEI индекс

\begin{tabular}{|c|c|c|c|c|c|c|}
\hline Предикторы & Модель 1 & Модель 2 & Модель 3 & Модель 4 & Модель 5 & Модель 6 \\
\hline Пол (1=жен.) & $\begin{array}{c}3,106 \\
(2,819)\end{array}$ & $\begin{array}{c}4,104 \\
(2,799)\end{array}$ & $\begin{array}{c}3,340 \\
(2,319)\end{array}$ & $\begin{array}{c}-1,884 \\
(1,735)\end{array}$ & $\begin{array}{l}0,0569 \\
(1,605)\end{array}$ & \\
\hline 30-39 лет ${ }^{12}$ & $\begin{array}{c}2,122 \\
(4,108)\end{array}$ & $\begin{array}{c}3,491 \\
(4,162)\end{array}$ & $\begin{array}{c}1,333 \\
(3,592)\end{array}$ & $\begin{array}{l}3,679 * \\
(2,104)\end{array}$ & $\begin{array}{c}2,103 \\
(2,436)\end{array}$ & \\
\hline 40-49 лет & $\begin{array}{l}-3,794 \\
(4,645)\end{array}$ & $\begin{array}{l}-1,755 \\
(4,409)\end{array}$ & $\begin{array}{l}-1,884 \\
(3,934)\end{array}$ & $\begin{array}{l}-0,353 \\
(2,112)\end{array}$ & $\begin{array}{l}-2,406 \\
(2,546)\end{array}$ & \\
\hline 50-59 лет & $\begin{array}{c}3,999 \\
(4,608)\end{array}$ & $\begin{array}{c}5,322 \\
(4,467)\end{array}$ & $\begin{array}{c}4,800 \\
(3,663)\end{array}$ & $\begin{array}{l}4,126^{*} \\
(2,442)\end{array}$ & $\begin{array}{l}5,318 * * \\
(2,576)\end{array}$ & \\
\hline 60-69 лет & $\begin{array}{c}1,943 \\
(4,682)\end{array}$ & $\begin{array}{c}1,956 \\
(4,677)\end{array}$ & $\begin{array}{c}2,291 \\
(4,054)\end{array}$ & $\begin{array}{c}1,653 \\
(2,312)\end{array}$ & $\begin{array}{c}2,336 \\
(2,772)\end{array}$ & \\
\hline 70-79 лет & $\begin{array}{l}11,110 \\
(9,140)\end{array}$ & $\begin{array}{c}12,830 \\
(9,448)\end{array}$ & $\begin{array}{c}-3,529 \\
(10,39)\end{array}$ & $\begin{array}{c}10,75^{* *} \\
(4,242)\end{array}$ & $\begin{array}{c}6,831 \\
(6,668)\end{array}$ & \\
\hline Работа в университете & $\begin{array}{c}3,016 \\
(2,570)\end{array}$ & & & & & \\
\hline Работа в НКО & $\begin{array}{c}-6,188 * * \\
(2,436)\end{array}$ & & & & & \\
\hline $\begin{array}{l}\text { Плохо знаком с выборами } \\
\text { в регионе }^{13}\end{array}$ & $\begin{array}{c}3,842 \\
(2,683)\end{array}$ & & & & & \\
\hline $\begin{array}{l}\text { Хорошо знаком с выборами } \\
\text { в регионе }\end{array}$ & $\begin{array}{l}6,392 * * \\
(3,008)\end{array}$ & & & & & \\
\hline «Инсайдер» & & $\begin{array}{l}-4,004 \\
(2,746)\end{array}$ & & & & \\
\hline $\begin{array}{l}\text { Голосовал за проигравшую партию } \\
\text { или проигравшего кандидата }\end{array}$ & & & $\begin{array}{c}-22,3 * * * \\
(3,258)\end{array}$ & & $\begin{array}{l}-5,63 * * \\
(2,266)\end{array}$ & $\begin{array}{c}-7,37 * * * \\
(2,272)\end{array}$ \\
\hline Отказ от ответа & & & $\begin{array}{l}-6,148 \\
(6,741)\end{array}$ & & $\begin{array}{c}1,876 \\
(3,869)\end{array}$ & $\begin{array}{l}-0,243 \\
(4,219)\end{array}$ \\
\hline Испортил бюллетень & & & $\begin{array}{c}-16,2 * * * \\
(3,375)\end{array}$ & & $\begin{array}{l}-1,199 \\
(2,314)\end{array}$ & $\begin{array}{l}-3,309 \\
(2,405)\end{array}$ \\
\hline Доверие телевидению & & & & $\begin{array}{c}2,052 * * * \\
(0,426)\end{array}$ & & \\
\hline Доверие системе избиркомов & & & & $\begin{array}{c}3,070 * * * \\
(0,345)\end{array}$ & & \\
\hline Индекс доверия & & & & & $\begin{array}{c}45,57 * * * \\
(2,929)\end{array}$ & $\begin{array}{c}44,62 * * * \\
(3,225)\end{array}$ \\
\hline Ү-пересечение & $\begin{array}{l}43,85 * * * \\
(5,127)\end{array}$ & $\begin{array}{c}48,72 * * * \\
(4,144)\end{array}$ & $\begin{array}{c}65,80 * * * \\
(4,853)\end{array}$ & $\begin{array}{c}30,30 * * * \\
(1,929)\end{array}$ & $\begin{array}{c}39,07 * * * \\
(3,308)\end{array}$ & $\begin{array}{c}42,57 * * * \\
(2,670)\end{array}$ \\
\hline $\mathbf{N}$ & 170 & 165 & 172 & 170 & 169 & 169 \\
\hline $\mathbf{R}^{2}$ & 0,133 & 0,083 & $\mathbf{0 , 3 0 7}$ & 0,692 & 0,675 & 0,642 \\
\hline
\end{tabular}

Примечание: в ячейках отражены нестандартизированные b-коэффициенты; в скобках - стандартные ошибки; p-values: *** $-0,01 ; * *-0,05 ; *-0,1$.

12 Опорная категория - 20-29 лет.

13 Опорная категория - «отлично знаком с выборами в регионе». 
Доверие телевидению, а также системе избирательных комиссий сильно и статистически значимо связано с тем, как эксперт оценивает качество выборов. Одна единица увеличения доверия по шкале от 0 до 10 влечет увеличение оценки выборов на 2 пункта по шкале от 1 до 100; доверия избирательных комиссиям - на 3 пункта. Индекс доверия в целом варьирует от 0 до 1, соответственно переход от 0 к 1 увеличивает значение PEI индекса на 45 пунктов. Примечательно, что сила эффекта доверия телевидению одинакова среди всех групп экспертов, независимо от стратегии голосования (проще говоря, среди проигравших более доверяющие оценивали выборы выше).

Также стоит уделить внимание объяснительной силе моделей, поскольку именно процент объясненной вариации указывает на то, насколько успешно мы можем детектировать источник возможных смещений. Модели 4-6 объясняют от 64 до 69\% вариации: иными словами, доверие и стратегия голосования трактуют подавляющую часть вариации. Диагностика регрессионных остатков свидетельствует о том, что они принимают форму распределения близкого к нормальному, т.е. оставшаяся необъясненная вариация - это, вероятно, «белый шум».

Еще одним важным аспектом является то, какова дисперсия оценок по каждому из регионов, насколько экспертные оценки расходятся в каждом из них. Наименьший разброс наблюдался в Белгородской области, а также в регионах, где количество экспертов было незначительным (Магаданская область, Еврейская АО, Курганская область, Калужская область). Проблема неравномерного распределения экспертов по регионам стала неизбежной, поскольку регионы характеризуются крайней неравномерностью с точки зрения численности, уровня экономического развития, плотности покрытия университетами и состоянием экспертного сообщества. Наконец, в некоторых моделях могут иметь значение случаи с аномально высокими или низкими значениями ${ }^{14}$ и статистические выбросы (outliers), т.е. случаи, не вписывающиеся в общую тенденцию. Так, с помощью методов диагностики влиятельных случаев и выбросов было сделано одно наблюдение, где эксперт при низком уровне доверия политическим институтам оценил выборы в Татарстане очень высоко. Этот случай является выбросом для предиктора «индекс доверия» и влиятельным случаем для предиктора «стратегия голосования» (эксперт отказался отвечать, как он проголосовал). Результаты анализа без данного наблюдения показывают, что обнаруженный паттерн никак не изменился и даже стал более отчетливым.

Совместное распределение уровня доверия и стратегий голосования также дает возможность типологизировать экспертов по этим двум переменным (рисунок 11 и таблица 2). Большинство экспертов составляют группу недоверяющих власти «проигравших», затем идут недоверяющие власти «нигилисты», испортившие бюллетени, самые малочисленные категории экспертов - недоверяющие «победители» (всего 6 чел.), уклонившиеся от ответа о голосовании (8 чел.). Есть основания полагать, что доверие и стратегия голосования связаны, однако эта связь не столь отчетлива. Среди доверяющих власти экспертов оказалось больше «победителей» и меньше «проигравших», среди испортивших бюллетень также выявлено меньше доверяющих (14 из 60 чел.).

14 Например, в Республике Коми, Курганской и Рязанской областях некоторые эксперты оценивали выборы слишком оптимистично на фоне средней оценки по региону. 

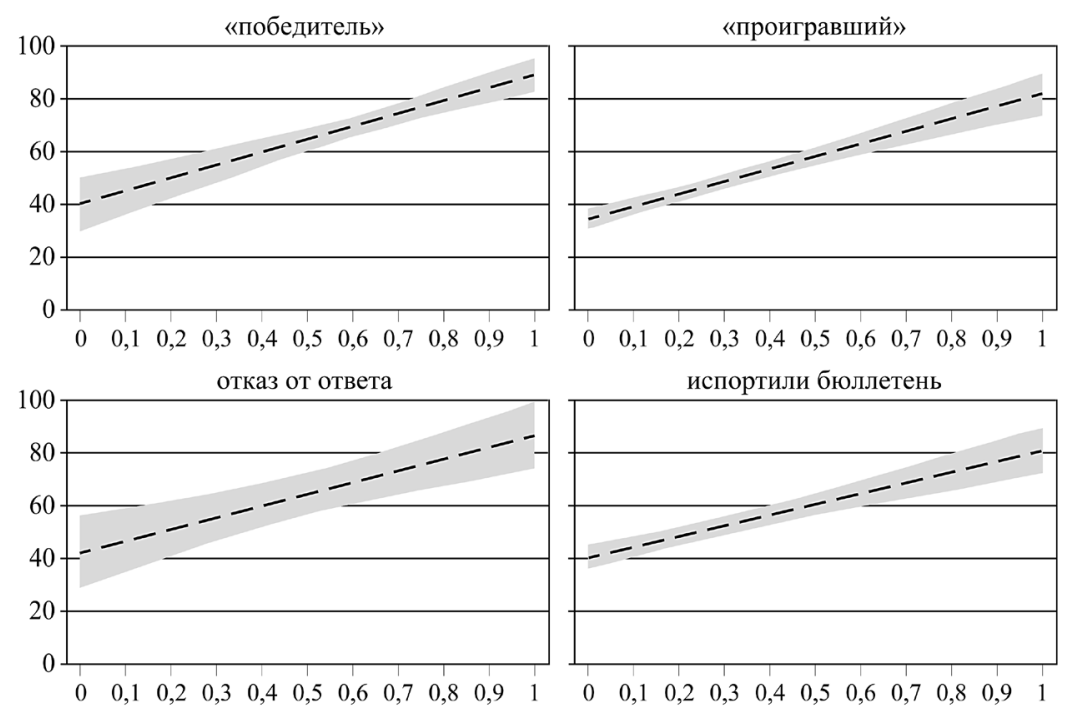
Рисунок 11. Предсказанные значения РЕI индекса в зависимости от уровня доверия и стратегии голосования

\section{Таблица 2. Типология экспертов в зависимости от стратегии голосования и доверия политическим институтам}

\begin{tabular}{|c|c|c|c|c|c|}
\hline & \multicolumn{4}{|c|}{ Стратегия голосования } & \multirow[b]{2}{*}{ Всего } \\
\hline & «Победитель» & «Проигравший» & Отказ от ответа & $\begin{array}{l}\text { Испортил } \\
\text { бюллетень }\end{array}$ & \\
\hline $\begin{array}{l}\text { Низкий уровень } \\
\text { доверия }^{15}\end{array}$ & 6 & 70 & 6 & 47 & 129 \\
\hline $\begin{array}{l}\text { Высокий уровень } \\
\text { доверия }\end{array}$ & 14 & 14 & 2 & 13 & 43 \\
\hline Всего & 20 & 84 & 8 & 60 & 172 \\
\hline
\end{tabular}

$\mathrm{X}^{2}=25,07 ;$ p-value $-0,00$.

В дальнейшем эта типология может быть использована как инструмент диагностики возможных смещений экспертных оценок в условиях «электорального авторитаризма», а также применима и на агрегированном уровне в качестве контрольных переменных (средний уровень доверия, доля «проигравших и победивших» в регионе).

15 Переменная получена путем дихотомизации интервального индекса доверия. Значения от 0 до 0,4 включительно кодировались как 0 , значения выше 0,4 - как 1 . 


\section{Заключение}

На основе данных экспертного опроса международного проекта Electoral Integrity Project мы показали, что российские региональные эксперты, оценивающие качество выборов в регионах в сентябре 2015 г., в первую очередь должны быть описаны сквозь призму «лояльность-оппозиционность». Среди ключевых переменных, которые мы рассмотрели (идеологическая ориентация, опыт участия в подготовке или проведении выборов, доверие правительству, доверие телевизионному эфиру, собственное голосование экспертов на этих выборах, ценностное/прагматическое отношение к институту выборов), значение имеют те, которые дают основание определить позицию эксперта по отношению к политическому режиму.

Мы считаем, что предмет и выводы настоящей статьи могут представлять особый интерес для исследователей, занимающихся проблематикой имплементации «электорального авторитаризма» к посткоммунистическим режимам, и особенно для тех из них, чей интерес лежит в области динамики субнационального авторитаризма в отношении различных групп граждан и проблемы легитимности режима.

\section{Литература}

Гельман В.Я. (2012) Расцвет и упадок электорального авторитаризма в России // Полития. № 4. С. $65-88$.

Голосов Г.В. (2008) Электоральный авторитаризм в России // Pro et Contra. № 1. С. 22-35. Гражданин наблюдатель в Новгородской области (б/г) // ВКонтакте // https://vk.com/gn novgorod Дальневосточный наблюдатель (б/г) // VKontakte.com // https://vk.com/nabludatel khhv

Завадская М.А., Савельева Н. (2014) «А можно я как-нибудь сам выберу?»: выборы как «личное дело», процедурная легитимность и мобилизация 2011-2012 // Ерпылева С.В., Магун А.В. (ред.) Политика аполитичных: гражданские движения в России 2011-2013 гг. М.: НЛО. С. 219-268.

Международные наблюдатели о выборах в России (2011) // Радио Свобода // http://www.svoboda.org/a/24416155.html

Многообразие демократии (2017) // V-Dem.net // https://www.v-dem.net/ru/

Панов П.В. (2008) Выборы в России: институциональная перспектива // Полис. № 5. С. 99-112.

Павлова Т.В., Патрушев С.В., Филиппова Л.Е. (2012) Гражданское и политическое в российских общественных практиках: перспектива институциональной дифференциации // Вестник Института социологии. № 4. С. 119-137.

Пермский наблюдатель (б/r) // VKontakte.com // https://vk.com/permnab

По мнению наблюдателей ПАСЕ, результаты выборов в России отражают волю народа (2008) // Радио Свобода // http://www.svoboda.org/a/437571.html

Титков А.С. (2013) Политические регионалисты 1990-2000-х: динамика аналитического сообщества // Зайцев Д.Г., Какабадзе Ш.Ш. (ред.) Аналитические сообщества в публичной политике: глобальный феномен и российские практики. М.: РОССПЭН. С. 110-121.

Турченко М.С. (2015) Почему честные выборы не пустой звук // Полис. № 5. С. 186-191.

Acemoglu D., Egorov G., Sonin K. (2010) Political Selection and Persistence of Bad Governments // The Quarterly Journal of Economics, no 4, pp. 1511-1575.

Analytical Report №1. Local Elections on September 13, 2015 Russian Federation (2015) // Golosinfo.org // http://www.golosinfo.org/en/articles/31331

Birch S. (2011) Electoral Malpractice, Oxford University Press. 
Budge I. (2001) Mapping Policy Preferences: Estimates for Parties, Electors, and Governments, 1945-1998. Vol. 1, Oxford University Press on Demand.

Castles F., Mair P. (1984) Left-Right Political Scales: Some Expert Judgments // European Journal of Political Research, no 12, pp. 73-88.

Elklit J., Svensson P. (1997) What Makes Elections Free and Fair? // Journal of Democracy, no 3, pp. 32-46.

Freedom of the Press in Russia in 2016 (2016) // Freedom House // https://freedomhouse.org/report/freedom-press/2016/russia

Gelman A. (2017) About that Bogus Claim that North Carolina is no Longer a Democracy... // Andrewgelman.com // http://andrewgelman.com/2017/01/02/about-that-bogus-claim-thatnorth-carolina-is-no-longer-a-democracy/

Gel'man V. (2015) Authoritarian Russia. Analyzing Post-Soviet Regime Changes, Pittsburgh University Press.

Gibson E.L. (2013) Boundary Control: Subnational Authoritarianism in Federal Democracies, Cambridge University Press.

Golosov G. (2011) The Regional Roots of Electoral Authoritarianism in Russia // Europe-Asia Studies, vol. 63, no 4, pp. 623-639.

Golosov G. (2016) The September 2015 Regional Elections in Russia: A Rehearsal for Next Year's National Legislative Races // Regional and Federal Studies, vol. 26, no 2, pp. 255-268.

Goode P. (2010) Redefining Russia: Hybrid Regimes, Fieldwork, and Russian Politics // Perspectives on Politics, vol. 8, no 4, pp. 1055-1075.

Greene S. (2014) Moscow in Movement: Power and Opposition in Putin's Russia, Stanford University Press.

Huber J., Inglehart R. (1995) Expert Interpretations of Party Space and Party Locations in 42 Societies // Party Politics, vol. 1, no 1, pp. 73-111.

Kitschelt H. (1995) Formation of Party Cleavages in Post-Communist Democracies Theoretical Propositions // Party Politics, vol. 1, no 4, pp. 447-472.

Kuran T. (1997) Private Truths, Public Lies: The Social Consequences of Preference Falsification, Harvard University Press.

Lehoucq F. (2003) Electoral Fraud: Causes, Types, and Consequences // Annual Review of Political Science, vol. 6, pp. 233-256.

Levitsky S., Way L.A. (2010) Competitive Authoritarianism: Hybrid Regimes after the Cold War, New York: Cambridge University Press

Mair P. (2001) Searching for the Positions of Political Actors // Estimating the Policy Position of Political Actors (ed. Laver M.), London: Routledge, pp. 11-30.

Manifesto Project (2016) // https://manifestoproject.wzb.eu/

Manin B., Przeworski A., Stokes S. (1999) Elections and Representation // Democracy, Accountability, and Representation (eds. Przeworski A., Stokes S.C., Manin B.), New York: Cambridge University Press, pp. 29-54.

Marks G., Hooghe L., Loveless M., Rohrschneider R., Steenbergen M., Vachudova M., Whitefield S. (2007) Do Expert Surveys Produce Consistent Estimates of Party Stances on European Integration? Comparing Expert Surveys in the Difficult Case of Central and Eastern Europe // Electoral Studies, no 26, pp. 23-38.

Nikolayenko O. (2015) Do Contentious Elections Depress Turnout // Contentious Elections: From Ballots to Barricades (eds. Norris P., Frank R.W., Martinez i Coma F.), New York: Routledge, pp. 25-44.

Norris P. (2013) The New Research Agenda Studying Electoral Integrity // Electoral Studies, no 4, pp. 563-575.

Norris P. (2014) Why Electoral Integrity Matters, Cambridge University Press.

Powell G.B. (2000) Elections as Instruments of Democracy: Majoritarian and Proportional Visions, Yale University Press.

Schedler A. (2002) The Menu of Manipulation // Journal of Democracy, no 2, pp. 36-50.

Schedler A. (ed.) (2006) Electoral Authoritarianism: The Dynamics of Unfree Competition, London: Lynne Rienner.

Sedziaka A.A., Rose R. (2014) Unfair Elections and Support for Electoral Protest // University of Strathclyde Studies in Public Policy, no 510// http://www.cspp.strath.ac.uk/view_item.php?id=510 
Steenbergen M., Marks G. (2007) Evaluating Expert Judgments // European Journal of Political Research, vol. 46, no 3, pp. 347-366.

The Electoral Integrity Project // https://sites.google.com/site/electoralintegrityproject4/home

The Data "Quality of Government" (2016) // The Quality of Government Institute // http://qog.pol.gu.se/data

van Ham C. (2015) Getting Elections Right? Measuring Electoral Integrity // Democratization, vol. 22, no 4, pp. 714-737.

Whitefield S., Vachudova M.A., Steenbergen M.R., Rohrschneider R., Marks G., Loveless M.P., Hooghe L. (2007) Do Expert Surveys Produce Consistent Estimates of Party Stances on European Integration? Comparing Expert Surveys in the Difficult Case of Central and Eastern Europe // Electoral Studies, vol. 26, no 1, pp. 50-61.

\title{
Elections in Russia - Who Evaluates Them and How: The Specifics of the Expert Survey on Russian Regional Elections on September 13, 2015 ${ }^{16}$
}

\author{
M. ZAVADSKAYA*, V. BEDERSON**
}

\begin{abstract}
*Margarita Zavadskaya - Senior Researcher, Laboratory for Comparative Social Studies, National Research University Higher School of Economics; the European University at Saint Petersburg. Address: 55, Sedova St., Saint Petersburg, 191187, Russian Federation. E-mail: mzavadskaya@hse.ru

**Vsevolod Bederson - PhD in Politics, Junior Research Fellow, Institute of Philosophy and Law, Ural Branch of the Russian Academy of Sciences; Fellow, Center for Comparative History and Political Studies, Perm State University; Senior Lecturer, Political Science Department, Perm State University. Address: 16, Kovalevskaya St., Ekaterinburg, 620990, Russian Federation. E-mail: vsbederson@gmail.com
\end{abstract}

Citation: Zavadskaya M., Bederson V. (2018) Elections in Russia - Who Evaluates Them and How: The Specifics of the Expert Survey on Russian Regional Elections on September 13, 2015. Mir Rossii, vol. 27, no 3, pp. 82-106 (in Russian). DOI: 10.17323/1811-038X-2018-27-3-82-106

\begin{abstract}
Evaluation based on expert surveys is widespread in comparative research. However, the reliability and validity of the results obtained from such surveys may depend on 1) the politicization of the subject of study (i.e. the problem of sensitivity), 2) the current political regime (Russia is characterized by experts as 'electoral authoritarianism') and 3) the ongoing process of the professionalization of the expert community. The authors suggest that all three systematically affect the quality of expertise and are the

\footnotetext{
16 The article was prepared within the framework of the Basic Research Program at the National Research University Higher School of Economics (HSE) and supported within the framework of a subsidy by the Russian Academic Excellence Project '5-100'.
} 
sources of specific biases which must be recognized when dealing with expert surveys in appropriate contexts. Empirically this study draws on the expert surveys conducted within the framework of the international Electoral Integrity Project. The authors find that the spread of expert opinions depends on the experts' ideological preferences, their confidence in the existing political institutions, individual voting strategy (ruling party vs. opposition), and the degree of confidence in television. On a more general level, the article provides a description of the state of the modern Russian expert community in the field of electoral expertise.

Key words: systematic bias, expert survey, elections, electoral authoritarianism, Russia, regional politics, research methods

\section{References}

Acemoglu D., Egorov G., Sonin K. (2010) Political Selection and Persistence of Bad Governments. The Quarterly Journal of Economics, no 4, pp. 1511-1575.

Analytical Report №1. Local Elections on September 13, 2015 Russian Federation (2015). Golosinfo.org. Available at: http://www.golosinfo.org/en/articles/31331, accessed 31 May 2018.

Birch S. (2011) Electoral Malpractice, Oxford University Press.

Budge I. (2001) Mapping Policy Preferences: Estimates for Parties, Electors, and Governments, 1945-1998. Vol. 1, Oxford University Press on Demand.

Castles F., Mair P. (1984) Left-Right Political Scales: Some Expert Judgments. European Journal of Political Research, no 12, pp. 73-88.

Dal'nevostochnyj nablyudatel' (n/y) [The Far East Observer]. VKontakte.com. Available at: https://vk.com/nabludatel khv, accessed 31 May 2018.

Elklit J., Svensson P. (1997) What Makes Elections Free and Fair? Journal of Democracy, no 3, pp. 32-46.

Freedom of the Press in Russia in 2016 (2016). Freedom House. Available at: https://freedomhouse.org/report/freedom-press/2016/russia, accessed 31 May 2018.

Gelman A. (2017) About that Bogus Claim that North Carolina is no Longer a Democracy... Andrewgelman.com. Available at: http://andrewgelman.com/2017/01/02/about-that-bogusclaim-that-north-carolina-is-no-longer-a-democracy/, accessed 31 May 2018.

Gel'man V.Ya. (2012) Rastsvet i upadok elektoral'nogo avtoritarizma v Rossii [The Rise and Decline of Electoral Authoritarianism in Russia]. Politiya, no 4, pp. 65-88.

Gel'man V. (2015) Authoritarian Russia. Analyzing Post-Soviet Regime Changes, Pittsburgh University Press.

Gibson E.L. (2013) Boundary Control: Subnational Authoritarianism in Federal Democracies, Cambridge University Press.

Golosov G.V. (2008) Elektoral'nyj avtoritarizm v Rossii [Electoral Authoritarianism in Russia]. Pro et Contra, no 1, pp. 22-35.

Golosov G. (2011) The Regional Roots of Electoral Authoritarianism in Russia. Europe-Asia Studies, vol. 63, no 4, pp. 623-639.

Golosov G. (2016) The September 2015 Regional Elections in Russia: A Rehearsal for Next Year's National Legislative Races. Regional and Federal Studies, vol. 26, no 2, pp. 255-268.

Goode P. (2010) Redefining Russia: Hybrid Regimes, Fieldwork, and Russian Politics. Perspectives on Politics, vol. 8, no 4, pp. 1055-1075.

Grazhdanin nablyudatel' v Novgorodskoj oblasti (n/y) [Citizen-observer in Novgorod Region]. VKontakte.com. Available at: https://vk.com/gn_novgorod, accessed 31 May 2018. 
Greene S. (2014) Moscow in Movement: Power and Opposition in Putin's Russia, Stanford University Press.

Huber J., Inglehart R. (1995) Expert Interpretations of Party Space and Party Locations in 42 Societies. Party Politics, vol. 1, no 1, pp. 73-111.

Kitschelt H. (1995) Formation of Party Cleavages in Post-Communist Democracies Theoretical Propositions. Party Politics, vol. 1, no 4, pp. 447-472.

Kuran T. (1997) Private Truths, Public Lies: The Social Consequences of Preference Falsification, Harvard University Press.

Lehoucq F. (2003) Electoral Fraud: Causes, Types, and Consequences. Annual Review of Political Science, vol. 6, pp. 233-256.

Levitsky S., Way L.A. (2010) Competitive Authoritarianism: Hybrid Regimes after the Cold War, New York: Cambridge University Press

Mair P. (2001) Searching for the Positions of Political Actors. Estimating the Policy Position of Political Actors (ed. Laver M.), London: Routledge, pp. 11-30.

Manifesto Project (2016). Available at: https://manifestoproject.wzb.eu/, accessed 31 May 2018.

Manin B., Przeworski A., Stokes S. (1999) Elections and Representation. Democracy, Accountability, and Representation (eds. Przeworski A., Stokes S.C., Manin B.), New York: Cambridge University Press, pp. 29-54.

Marks G., Hooghe L., Loveless M., Rohrschneider R., Steenbergen M., Vachudova M., Whitefield S. (2007) Do Expert Surveys Produce Consistent Estimates of Party Stances on European Integration? Comparing Expert Surveys in the Difficult Case of Central and Eastern Europe. Electoral Studies, no 26, pp. 23-38.

Mezhdunarodnye nablyudateli o vyborakh v Rossii (2011) [International Observers about Elections in Russia]. Radio Svoboda. Available at: http://www.svoboda.org/a/24416155.html, accessed 31 May 2018.

Mnogoobrazie demokratii (2017) [Diversity of Democracy]. V-Dem.net. Available at: https://www.v-dem.net/ru/, accessed 31 May 2018.

Nikolayenko O. (2015) Do Contentious Elections Depress Turnout. Contentious Elections: From Ballots to Barricades (eds. Norris P., Frank R.W., Martinez i Coma F.), New York: Routledge, pp. 25-44.

Norris P. (2013) The New Research Agenda Studying Electoral Integrity. Electoral Studies, no 4, pp. 563-575.

Norris P. (2014) Why Electoral Integrity Matters, Cambridge University Press.

Panov P.V. (2008) Vybory v Rossii: institutsional'naya perspektiva [Elections in Russia: Institutional Perspective]. Polis, no 5, pp. 99-112.

Pavlova T.V., Patrushev S.V., Filippova L.E. (2012) Grazhdanskoe i politicheskoe v rossijskikh obshchestvennykh praktikakh: perspektiva institutsional'noj differentsiatsii [The Civil and Political in Russian Civic Practices: Perspectives of Institutional Differentiation]. Vestnik Instituta sotsiologii, no 4, pp. 119-137.

Permskij nablyudatel' (n/y) [The Perm Observer]. VKontakte.com. Available at: https://vk.com/permnab, accessed 31 May 2018.

Po mneniyu nablyudatelej PASE, rezul'taty vyborov v Rossii otrazhayut volyu naroda (2008) [According to PASE Observers The Results of Russian Elections Reflect the Will of the People]. Radio Svoboda. Available at: http:/www.svoboda.org/a/437571.html, accessed 31 May 2018.

Powell G.B. (2000) Elections as Instruments of Democracy: Majoritarian and Proportional Visions, Yale University Press.

Schedler A. (2002) The Menu of Manipulation. Journal of Democracy, no 2, pp. 36-50.

Schedler A. (ed.) (2006) Electoral Authoritarianism: The Dynamics of Unfree Competition, London: Lynne Rienner.

Sedziaka A.A., Rose R. (2014) Unfair Elections and Support for Electoral Protest. University of Strathclyde Studies in Public Policy, no 510. Available at: http://www.cspp.strath.ac.uk/view_item.php?id=510, accessed 31 May 2018.

Steenbergen M., Marks G. (2007) Evalüating Expert Judgments. European Journal of Political Research, vol. 46, no 3, pp. 347-366. 
The Data "Quality of Government" (2016). The Quality of Government Institute. Available at: http://qog.pol.gu.se/data, accessed 31 May 2018.

The Electoral Integrity Project. Available at: https://sites.google.com/site/electoralintegrityproject4/home, accessed 31 May 2018.

Titkov A.S. (2013) Politicheskie regionalisty 1990-2000-kh: dinamika analiticheskogo soobshchestva [Political Regionalists in 1990s-2000s: the Dynamics of the Analytical Community]. Analiticheskie soobshchestva $v$ publichnoj politike: global'nyj fenomen $i$ rossijskie praktiki [Analytical Community in Public Politics: the Global Phenomenon in the Russian Practice] (eds. Zajtsev D.G., Kakabadze Sh.Sh.), Moscow: ROSSPEN, pp. 110-121.

Turchenko M.S. (2015) Pochemu chestnye vybory ne pustoj zvuk [Why Fair Elections Are not Fake]. Polis, no 5, pp. 186-191.

van Ham C. (2015) Getting Elections right? Measuring Electoral Integrity. Democratization, vol. 22, no 4, pp. 714-737.

Whitefield S., Vachudova M.A., Steenbergen M.R., Rohrschneider R., Marks G., Loveless M.P., Hooghe L. (2007) Do Expert Surveys Produce Consistent Estimates of Party Stances on European Integration? Comparing Expert Surveys in the Difficult Case of Central and Eastern Europe. Electoral Studies, vol. 26, no 1, pp. 50-61.

Zavadskaya M.A., Savel'eva N. (2014) «A mozhno ya kak-nibud' sam vyberu?»: vybory kak «lichnoe delo», protsedurnaya legitimnost' i mobilizatsiya 2011-2012 ['Can I Choose for Myself?': Elections as a 'Private Matter', Procedural Legitimacy and Mobilization in 20112012]. Politika apolitichnykh: grazhdanskie dvizheniya v Rossii 2011-2013 gg [Politics of the Apolitical: Civic Movements in Russia 2011-2013] (eds. Erpyleva S.V., Magun A.V.), Moscow: NLO, pp. 219-268. 